ARTIKEL PENELITIAN

\title{
HUBUNGAN DEPRESI DENGAN KUALITAS HIDUP WANITA MENOPAUSE DI KLINIK BANK TABUNGAN PENSIUNAN NASIONAL (BTPN) SAMARINDA TAHUN 2018
}

\author{
Nilam Noorma ${ }^{1)}$, Ratanto ${ }^{2)}$, Diesteyera Putri Anggraini ${ }^{3)}$ \\ 1)2)3) Keperawatan, Program Studi D IV Keperawatan Poltekkes Kemenkes Kalimantan \\ Timur, Jl. Wolter Monginsidi No. 38 Samarinda Kode Pos 75123 \\ Email : ns.nilamnoorma@gmail.com
}

\begin{abstract}
Depression is a serious mental condition that signified by feeling of sadness and anxiety one of which could affect the life quality of women with menopause. Out of 7 women with menopause at BTPN clinic, 5 of them are suffering with depression. This research is aimed to know the relation between depression with the life quality of women with menopause. A quantitative research with analytical study and cross sectional research design. Population of 1244 people. A sample of 62 people using Consecutive Sampling technique. The instrument that used for measure of depression is standard questionnaire of Beck Depression Inventory made by Dr. Aaron T. Beck and the instrument that used for life quality is standard questionnaire of WHOQL made by World Health Organization. Subjective data is taken during the interview, continued by filling in the questionnaire. Furthermore, the data is analyzed in univariate and bivariate fashion with Chi Square test. The result is Scores obtained from variable of depression is $\mathrm{p}=0,004(\mathrm{p}<0,05)$, thus, there is a relation between depression with the life quality of women with menopause. The conclusion There is a relation between depression with the life quality of women with menopause it is suggested for clinic of BTPN to do counseling about menopause with the intention of improving life quality.
\end{abstract}

\section{Key Words : Depression, Life quality, Menopause}

\begin{abstract}
Abstrak
Depresi merupakan gangguan mental yang serius ditandai dengan perasaan sedih dan cemas yang salah satunya dapat mempengaruhi kualitas hidup wanita menopause. Dari 7 wanita menopause di Klinik BTPN, 5 di antaranya mengalami depresi. Penelitian ini bertujuan untuk mengetahui hubungan depresi dengan kualitas hidup wanita menopause. Jenis penelitian kuantitatif dengan studi analitik dan desain cross sectional. Populasi berjumlah 1244 orang. Sampel sebanyak 62 orang menggunakan teknik consecutive sampling. Instrumen yang digunakan untuk mengukur depresi berupa kuesioner baku Beck Depression Inventory yang dibuat oleh dr. Aaron T. Beck dan untuk kualitas hidup menggunakan kuesioner baku WHOQOL yang dibuat oleh WHO. Data subjektif diambil pada saat peneliti melakukan wawancara dilanjutkan dengan pengisian kuesioner. Kemudian data dianalisis secara univariat dan bivariat dengan uji Chi Square. Hasil penelitian didapatkan nilai dari variable depresi $p=0,004(p<0,05)$, sehingga ada hubungan antara depresi dengan kualitas hidup wanita menopause. Kesimpulan peneliian ini adalah Ada hubungan antara depresi dengan kualitas hidup wanita menopause. Disarankan untuk pihak Klinik BTPN untuk melakukan penyuluhan kesehatan tentang menopause dengan tujuan meningkatkan kualitas hidup.
\end{abstract}

Kata kunci : Depresi, Kualitas hidup, Menopause 


\section{PENDAHULUAN}

Seorang wanita yang memasuki masa menopause mengalami berbagai macam gejala. Tanda dan gejala dilihat dari aspek fisik dan psikologisnya. Gejala fisik meliputi menstruasi yang tidak teratur, rasa panas (hot flush), vagina menjadi kering, saluran uretra mengering dan menipis, berat badan meningkat, kurang tidur (insomnia) dan osteoporosis (Smart, 2014).

$$
\text { Gejala psikologis meliputi }
$$

perubahan emosi (perubahan suasana hati), perubahan kognitif (daya ingat menurun) dan depresi (Andira, 2012).

Dukungan pasangan hidup dalam hal ini dukungan suami juga mempengaruhi psikologis wanita menopause namun hal ini tidak memiliki hubungan signifikan dengan kualitas hidup wanita menopause (Noorma, 2017)

Depresi dan stres menjadi mitos umum untuk wanita yang memasuki usia paruh baya sehingga mereka menganggap depresi merupakan hal yang normal untuk wanita seusia mereka. Depresi berat tidak boleh dilihat sebagai suatu kejadian yang biasa, dan wanita yang menderita depresi pada masa tertentu dalam kehidupannya seharusnya menerima perhatian yang sama dengan penyakit lainnya. Ada masa transisi yang dikenal dengan perimenopause saat wanita menjadi lebih mudah mengalami depresi. Masa ini adalah masa saat periode menstruasi perlahan-lahan mulai berkurang dan menjadi jarang (Saputra, 2011).

Badan Kesehatan Dunia atau WHO (World Health Organization) menyebutkan bahwa diperkirakan di tahun 2030 ada sekitar 1,2 miliar perempuan yang berusia diatas 50 tahun (memasuki masa menopause) (World Health Organization, 2014). Di Indonesia, pada tahun 2025 diperkirakan akan ada 60 juta perempuan menopause. Pada tahun 2016 di Indonesia baru mencapai 14 juta perempuan menopause atau $7,4 \%$ dari total populasi yang ada. Angka harapan hidup perempuan melonjak dari 40 tahun pada tahun 1930 menjadi 67 tahun pada tahun 1998. Sementara perkiraan umur rata-rata usia menopause di Indonesia adalah 48 tahun. Peningkatan usia harapan hidup menyebabkan jumlah perempuan yang mengalami menopause semakin banyak (Dinkes, 2014).

Menurut Badan Pusat Statistik pada tahun 2015, jumlah penduduk wanita di Kalimantan Timur adalah 
1.809.833 jiwa. Dengan jumlah penduduk wanita pada kelompok umur 47-58 tahun dan diperkirakan telah memasuki usia menopause sebanyak 190.111 jiwa (Dinkes, 2016). Berdasarkan studi pendahuluan pada bulan November 2017 didapatkan data jumlah wanita di Klinik Bank Tabungan Pensiun Nasional sebanyak 1244 orang.

Berdasarkan hasil wawancara kepada 7 responden wanita menopause di klinik BTPN yang dilakukan peneliti pada tanggal 6 November 2017 didapatkan data dengan kesimpulan 5 wanita mengalami depresi dan 2 wanita lainnya tidak mengalami depresi.

Berdasarkan latar belakang dan fenomena yang sudah dijelaskan di atas, maka peneliti tertarik untuk meneliti tentang "Hubungan Depresi dengan Kualitas Hidup Wanita Menopause di Klinik Bank Tabungan Pensiun Nasional (BTPN) Samarinda”.

\section{METODE PENELITIAN}

\section{A. Lokasi Penelitian}

Penelitian dilaksanakan pada tanggal 2-3 Mei 2018 di Klinik Bank Tabungan Pensiun Nasional (BTPN) Samarinda.

\section{B. Rancangan Penelitian}

Penelitian ini menggunakan desain cross sectional.

\section{Populasi dan Sampel}

Populasi dari penelitian ini adalah nasabah di Klinik Bank Tabungan Pensiun Nasional (BTPN) Samarinda yang berjenis kelamin wanita berjumlah 1244 orang. Sampel dalam penelitian telah dihitung berdasarkan rumus sampel sebanyak 62 responden.

\section{Metode Pengumpulan Data}

Jenis data yang dikumpulkan berupa data primer dengan cara pengisian dua kuesioner (BDI-II dan WHOQOL). Dalam pengisian kuesioner, responden dipandu oleh peneliti. Skala untuk data kuesioner BDI-II dan data kuesioner kualitas hidup adalah kategorik (ordinal).

\section{E. Analisis Data}

Analisis univariat dilakukan pada variabel independen dan variabel dependen. Data numerik di deskripsikan menggunakan mean dan median, jika data numerik terdistribusi normal maka di gunakan mean dan standart deviasi. Sedangkan, data numerik yang tidak terdistribusi normal menggunakan 
median dan untuk data kategorik di deskripsikan dan menggunakan frekuensi. Analisa bivariat dilakukan terhadap dua variabel yang diduga berhubungan atau berkolerasi. Uji Chi Square yang digunakan untuk menguji hipotesis deskriptif bila dalam populasi terdiri atas dua kelas atau lebih dari dua kelas, data berbentuk ordinal dan sampelnya besar.

\section{HASIL PENELITIAN DAN PEMBAHASAN}

Tabel 1

Karakteristik Responden berdasarkan Umur Wanita Menopause di BTPN Samarinda

\begin{tabular}{ccc}
\multicolumn{3}{c}{ Tahun 2018} \\
\hline $\begin{array}{c}\text { Klasifikasi Umur } \\
\text { Responden } \\
\text { (Tahun) }\end{array}$ & $\begin{array}{c}\text { Frekuensi } \\
(\mathbf{n})\end{array}$ & $\begin{array}{c}\text { Presentase } \\
(\%)\end{array}$ \\
\hline $46-55$ & 9 & 14,5 \\
$56-65$ & 29 & 46,8 \\
$>65$ & 24 & 38,7 \\
Total & 62 & 100
\end{tabular}

Sumber : Analisa Data Primer, 2018

Berdasarkan

tabel

karakteristik respondenberdasarkan kelompok umur dengan presentase, hampir setengah responden memiliki kelompok umur 56-65 tahun (46,8\%), sedangkan masing-masing hampir setengah pada kelompok umur >65 tahun $(38,7 \%)$ dan sebagian kecil kelompok umur 46-55 tahun (14,5\%).
Karakteristik Responden berdasarkan

$$
\text { Paritas }
$$

Wanita Menopause di BTPN Samarinda Tahun 2018

\begin{tabular}{ccc}
\hline $\begin{array}{c}\text { Klasifikasi } \\
\text { Paritas } \\
\text { Responden } \\
\text { (Jumlah Anak) }\end{array}$ & $\begin{array}{c}\text { Frekuensi } \\
(\mathbf{n})\end{array}$ & $\begin{array}{c}\text { Presentase } \\
(\boldsymbol{\%})\end{array}$ \\
\hline $1-3$ & 34 & 54,8 \\
$4-6$ & 26 & 41,9 \\
$7-9$ & 2 & 3,2 \\
Total & 62 & 100 \\
\hline
\end{tabular}

Sumber : Analisa Data Primer, 2018

Berdasarkan tabel 2 di atas, pada karakteristik responden berdasarkan kelompok paritas didapatkan sebagian besar dengan jumlah anak 1-3 (54,8\%), hampir setengah responden dengan jumlah anak 4-6 (41,9\%) dan sebagian kecil responden dengan jumlah anak 7-9 $(3,2 \%)$.

Tabel 3

Karakteristik Responden berdasarkan Pendidikan TerakhirWanita Menopause di BTPN Samarinda Tahun 2018

\begin{tabular}{ccc}
\hline $\begin{array}{c}\text { Klasifikasi Pendidikan } \\
\text { Terakhir Responden }\end{array}$ & $\begin{array}{c}\text { Frekuensi } \\
(\mathbf{n})\end{array}$ & $\begin{array}{c}\text { Persentase } \\
(\boldsymbol{\%})\end{array}$ \\
\hline SD & 14 & 22,6 \\
SMP & 12 & 19,4 \\
SMA & 20 & 32,3 \\
Perguruan Tinggi & 16 & 25,8 \\
Total & 62 & 100 \\
\hline
\end{tabular}

Sumber : Analisa Data Primer, 2018

Berdasarkan tabel 3, karakteristik responden berdasarkan pendidikan terakhir didapatkan hampir setengah adalah SMA (32,3\%). Sedangkan, sebagian kecil adalah SMP $(19,4 \%)$.

Tabel 2 
Tabel 4

Distribusi Responden berdasarkan Depresi Wanita Menopause di BTPN Samarinda Tahun 2018

\begin{tabular}{ccc}
\hline $\begin{array}{c}\text { Distribusi } \\
\text { Depresi }\end{array}$ & $\begin{array}{c}\text { Frekuensi } \\
(\mathbf{n})\end{array}$ & $\begin{array}{c}\text { Persentase } \\
(\boldsymbol{\%})\end{array}$ \\
\hline Depresi & 27 & 43,5 \\
Tidak Depresi & 35 & 56,5 \\
Total & 77 & 100 \\
\hline
\end{tabular}

Sumber : Analisa Data Primer, 2018

Berdasarkan tabel 4 di atas, menunjukkan bahwa distribusi responden berdasarkan depresi sebagian besar adalah tidak depresi (56,5\%), Sedangkan, hampir setengahnya adalah depresi $(43,5 \%)$.

Tabel 5

Distribusi Responden berdasarkan Kualitas Hidup Wanita Menopause di BTPN Samarinda Tahun 2018

\begin{tabular}{ccc}
\hline $\begin{array}{c}\text { Distribusi } \\
\text { Kualitas Hidup }\end{array}$ & $\begin{array}{c}\text { Frekuensi } \\
(\mathbf{n})\end{array}$ & $\begin{array}{c}\text { Persentase } \\
(\boldsymbol{\%})\end{array}$ \\
\hline Baik & 32 & 51,6 \\
Kurang Baik & 30 & 48,4 \\
Total & 77 & 100 \\
\hline
\end{tabular}

Sumber : Analisa Data Primer, 2018

Berdasarkan tabel 5 di atas, menunjukkan bahwa distribusi responden berdasarkan kualitas hidup sebagian besar adalah baik (51,6\%), sedangkan hampir setengahnya adalah kurang baik $(48,4 \%)$.

Tabel 6

Hubungan Depresi dengan Kualitas Hidup Wanita Menopause di Klinik BTPN Samarinda Tahun 2018

\begin{tabular}{|c|c|c|c|c|c|c|c|}
\hline \multirow{4}{*}{ Depresi } & \multirow{2}{*}{\multicolumn{4}{|c|}{ Kualitas Hidup }} & \multirow{3}{*}{\multicolumn{2}{|c|}{ Total }} & \\
\hline & & & & & & & \multirow{3}{*}{$\begin{array}{l}\text { P sebanyak } 29 \text { orang }(46,8 \%) \text {. Distribusi } \\
\text { value } \\
\text { umur responden menunjukkan sebagian }\end{array}$} \\
\hline & \multicolumn{2}{|c|}{ Baik } & \multicolumn{2}{|c|}{$\begin{array}{c}\text { Kurang } \\
\text { Baik }\end{array}$} & & & \\
\hline & $\mathbf{N}$ & $\%$ & $\mathbf{N}$ & $\%$ & $\mathbf{n}$ & $\%$ & \\
\hline Depresi & 20 & 74,1 & 7 & 25 & 27 & 100 , & 0,00 tesar re \\
\hline
\end{tabular}

\begin{tabular}{llllccc}
\hline & & & 9 & & 0 \\
Tidak & 12 & 34,3 & 23 & 65, & 35 & 100, \\
Depresi & & & 7 & & 0 \\
\hline Sumber : Data Primer, 2018 & &
\end{tabular}

Berdasarkan hasil analisis bivariat pada tabel 6 di atas, responden yang mengalami depresi memiliki kualitas hidup baik $(74,1 \%)$, sedangkan yang mengalami depresi dengan kualitas hidup kurang baik (25,9\%). Pada responden yang tidak depresi dengan kualitas hidup baik (34,3\%), sedangkan responden yang tidak depresi dengan kualitas hidup kurang baik $(65,7 \%)$. Hasil analisis menggunakan uji chi-square diperoleh nilai $p$ value $=0,004$, yang berarti secara statistik ada hubungan depresi dengan kualitas hidup wanita menopause di Klinik Bank Tabungan Pensiun Nasional (BTPN) Samarinda.

\section{PEMBAHASAN}

\section{Analisis Univariat}

\section{Umur}

Karakteristik responden berdasarkan kelompok umur dengan presentase, hampir setengah responden memiliki kelompok umur 56-65 tahun

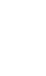

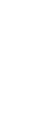


dalam kategori lansia akhir. Umur dikelompokkan berdasarkan kategori Depkes (2009). Penelitian ini didukung oleh Firmansyah (2014) yang menyatakan bahwa faktor yang mempengaruhi depresi adalah semakin tua umur.

Menurut asumsi peneliti semakin bertambahnya usia seseorang maka resiko terjadinya depresi juga akan meningkat. Karena, pada usia tersebut banyak perubahan yang terjadi pada diri seseorang meliputi perubahan fisik, psikologis, ekonomi, sosial dan spiritual.

\section{Paritas}

Karakteristik responden berdasarkan kelompok paritas didapatkan sebagian besar dengan jumlah anak 1-3 sebanyak 34 orang $(54,8 \%)$ dan hampir setengah responden dengan jumlah anak 4-6 sebanyak 26 orang (41,9\%). Namun hal ini tidak sejalan dengan penelitian Astari (2014) yang menunjukkan bahwa tidak terdapat hubungan antara paritas dengan kualitas hidup dan hubungan tersebut tidak bermakna secara statistik yang ditunjukkan dengan nilai p 0,668 $(>0,05)$ atau Ho ditolak yang berarti tidak ada hubungan antara paritas dengan kualitas hidup perempuan menopause.

Menurut asumsi peneliti, wanita dengan paritas sedikit maupun banyak belum tentu mempunyai dampak pada depresi dan kualitas hidupnya karena banyak faktor yang mempengaruhi seperti status sosial ekonomi dan tingkat pendidikan wanita menopause tersebut.

\section{Pendidikan Terakhir}

Karakteristik responden berdasarkan pendidikan terakhir didapatkan hampir setengah adalah SMA sebanyak 20 orang $(32,3 \%)$. Sedangkan, sebagian kecil adalah SMP sebanyak 12 orang $(19,4 \%)$.

Hal ini sejalan dengan Notoatmodjo (2010) yang menyatakan bahwa semakin tinggi tingkat pendidikan maka akan semakin mudah seseorang menerima hal yang baru dan akan mudah menyesuaikan diri. Pendapat lain juga disampaikan oleh Mandias (2012) yang menyatakan semakin tinggi pendidikan seseorang semakin mudah pula ia menerima informasi dan akhirnya makin banyak pula pengetahuan yang dimilikinya. Sebaliknya, jika tingkat pendidikan seseorang rendah maka akan menghambat perkembangan 
perilakunya terhadap penerimaan informasi dan pengetahuan yang baru.

Menurut asumsi peneliti tingkat pendidikan yang rendah sangat berhubungan dengan terjadinya depresi pada wanita menopause. Hal ini disebabkan oleh orang yang memiliki tingkat pendidikan yang rendah kurang terpapar dengan informasi sehingga cara mereka menanggapi suatu keadaan akan kurang baik, mereka cenderung putus asa dan pasrah dengan keadaan, perasaan seperti inilah yang akan memicu terjadinya depresi.

\section{Distribusi Variabel}

\section{Depresi}

Berdasarkan hasil penelitian menunjukkan bahwa sebagian besar responden tidak depresi sebanyak 35 orang $(56,5 \%)$ sedangkan hampir setengahnya adalah depresi sebanyak 27 orang (43,5\%). Depresi merupakan gangguan mental yang serius yang ditandai dengan perasaan sedih dan cemas. Gangguan ini biasanya akan menghilang dalam beberapa hari tetapi dapat juga berkelanjutan yang dapat mempengaruhi aktivitas sehari-hari (National Institute of Mental Health, 2010). Depresi merupakan gangguan mental yang ditandai dengan munculnya gejala penurunan mood, kehilangan minat terhadap sesuatu, perasaan bersalah, gangguan tidur atau nafsu makan, kehilangan energi dan penurunan konsentrasi (WHO, 2012). Salah satu faktor yang mempengaruhi tingkat depresi yaitu faktor biologis yang meliputi: jenis kelamin perempuan, defisiensi folat dan vitamin B12, dan penyakit kronis.

Hal ini sejalan dengan penelitian Firmansyah (2014) yang menyatakan bahwa lansia yang berjenis kelamin perempuan lebih beresiko mengalami depresi karena lansia perempuan akan mengalami menopause yang dapat menimbulkan perubahan fisik. Menurut asumsi peneliti tingkat depresi dapat terjadi pada wanita menopause karena pada saat wanita memasuki masa menopause akan terjadi perubahanperubahan yang akan dialami seperti berakhirnya masa reproduksi yang berarti berhentinya nafsu seksual, apalagi menyadari dirinya akan menjadi tua yang berarti kecantikannya akan memudar atau kehilangan daya tarik.

\section{Kualitas Hidup}

Berdasarkan hasil penelitian menunjukkan bahwa sebagian besar kualitas hidup baik sebanyak 32 orang 
$(51,6 \%)$ sedangkan hampir setengahnya kualitas hidup kurang baik sebanyak 30 orang $(48,4 \%)$. Kualitas hidup menurut World Health Organization Quality of Life (WHOQOL) Group (dalam Rapley, 2003), didefinisikan sebagai persepsi individu mengenai posisi individu dalam hidup dalam konteks budaya dan sistem nilai dimana individu hidup dan hubungannya dengan tujuan, harapan, standar yang ditetapkan dan perhatian seseorang.

Menurut penelitian Kargenti \& Marettih (2010) jika menopause dikaitkan dengan dimensi kualitas hidup yang telah dikeluarkan oleh WHO maka kualitas hidup perempuan yang menopause mengalami penurunan. Hal ini disebabkan ketika fase menopause, seluruh dimensi tersebut mengalami perubahan-perubahan. Fase ini terjadi berangsur-angsur yang semakin hari semakin jelas penurunan fungsi kelenjar indung telurnya. Secara psikologis, kekhawatiran ini berawal dari pemikiran bahwa dirinya akan tidak sehat, tidak bugar dan tidak cantik. Kondisi tersebut memang tidak menyenangkan bagi perempuan. Menurut asumsi peneliti kualitas hidup pada wanita menopause dapat mengalami perubahan karena pada fase tersebut wanita menopause mengalami penurunan fungsi organ tubuh, usia yang semakin tua dan rentan terhadap penyakit.

\section{Analisis Bivariat}

Hubungan Depresi dengan Kualitas Hidup Wanita Menopause

Berdasarkan hasil analisis menggunakan uji chi-square diperoleh nilai $\mathrm{p}$ value $=0,004$, yang berarti secara statistik ada hubungan depresi dengan kualitas hidup wanita menopause di Klinik Bank Tabungan Pensiun Nasional (BTPN) Samarinda.

Sejalan dengan penelitian yang dilakukan oleh Azzahro (2016) tentang hubungan tingkat depresi dengan kualitas hidup lanjut usia di Panti Wredha Darma Bhakti Pajang Surakarta. Hasil penelitian tersebut menunjukkan bahwa terdapat hubungan tingkat depresi dengan kualitas hidup lanjut usia. Responden dengan tingkat depresi yang tinggi memiliki kualitas hidup rendah. Penelitian lain dilakukan oleh Prihatnanto (2013) tentang hubungan antara tingkat depresi dengan kualitas hidup lansia di Desa Gedongan Sukoharjo. Penelitian ini menyimpulkan bahwa terdapat hubungan yang signifikan antara tingkat depresi dengan kualitas hidup lanjut usia di Desa 
Gedongan Kabupaten Sukoharjo $(\mathrm{p}=0,000)$.

Menurut asumsi peneliti, depresi yang di alami oleh wanita menapouse dapat mempengaruhi kualitas hidupnya karena pada keadaan menopause tersebut banyak perubahan-perubahan yang di alaminya. Seperti perubahan pada sistem reproduksinya, keadaan kesehatannya, maupun perubahanperubahan fisik lainnya. Wanita menopause beranggapan pada fase tersebut mereka sudah terlalu tua sehingga daya tarik atau merasa sudah tidak cantik lagi. Bahkan dari segi sosial ekonomi mereka biasanya sudah tidak mampu memenuhi kebutuhan nya sendiri sehingga harus berpangku tangan pada keluarga yang lain.

\section{SIMPULAN}

Karakteristik responden yang meliputi umur yaitu hampir setengah responden memiliki kelompok umur 5665 tahun sebanyak 29 orang, untuk kelompok paritas didapatkan sebagian besar dengan jumlah anak 1-3 sebanyak 34 orang dan untuk pendidikan terakhir didapatkan hampir setengah adalah SMA sebanyak 20 orang.

Distribusi depresisebagian besar tidak depresi sebanyak 35 orang di
Klinik Bank Tabungan Pensiun Nasional (BTPN) Samarinda. Distribusi kualitas hidup sebagian besar memiliki kualitas hidup baik sebanyak 32 orang di Klinik Bank Tabungan Pensiun Nasional (BTPN) Samarinda.

Berdasarkan hasil uji chi-square ada hubungan yang signifikan antara depresi dengan kualitas hidup wanita menopause di Klinik Bank Tabungan Pensiun Nasional (BTPN) Samarinda.

Hasil penelitian ini diharapkan menjadi landasan yang kuat untuk penelitian-penelitian yang selanjutnya. Saran untuk peneliti selanjutnya yaitu penelitian dapat dilakukan dengan waktu yang lebih panjang (misalnya 4 hari) mengingat dalam penelitian ini peneliti memiliki kendala dalam waktu pelaksanaan penelitian, serta dapat menggunakan jumlah responden yang lebih banyak (misalnya diatas 100 responden) agar mengurangi bias dalam penelitian dan diharapkan dapat membahas tingkatan depresi (depresi ringan, depresi sedang dan depresi berat).

\section{DAFTAR PUSTAKA}

Andira, D. (2012). Seluk Beluk Kesehatan Reproduksi Wanita. Yogyakarta: A Plus Books. 
Astari, R. Y., Tarawan, V. M., \& Sekarwana, N. (2014). Hubungan Antara Sindrom Menopause Dengan Kualitas Hidup Perempuan Menopause Di Puskesmas Sukahaji Kabupaten Majalengka, 42(3), 171-184.

Azzahro, F. D. (2016). Hubungan Antara Tinkat Depresi Dengan Kualitas Hidup Lanjut Usia Di Panti Wredha Darma Bhakti Pajang Surakarta.

Dinkes. (2016). Profil Kesehatan Kaltim Tahun 2015.

Dinkes, R. (2014). Profil Kesehatan Indonesia tahun 2014. Jakarta: Kemenkes RI.

Firmansyah, I. (2014). Hubungan Tingkat Depresi Dengan Kualitas Hidup Pada Lansia Di Kelurahan Jember Kidul Kecamatan Kaliwates Kabupaten Jember.

Kargenti, A., \& Marettih, E. (2010). Kualitas hidup perempuan menopause. Jurnal Kesehatan, 2, 192-200.

Mandias. (2012). Hubungan Tingkat Pendidikan Dengan Perilaku Masyarakat Desa Dalam Memanfaatkan Fasilitas Kesehatan Di Desa Pulisan Kecamatan Likupang Timur Minahasa Utara. Universitas Klabat.

National Institute of Mental Health. (2010). Depression and College Students. NIMH.

Nimas, A. F., \& Ambarini, T. K. (2012). Kualitas Hidup Pada
Penderita Kanker Serviks Yang Menjalani Pengobatan Radioterapi. Jurnal Psikologi Klinis Dan Kesehatan Mental, 1(2), 123-129.

Noorma, N. (2017). Faktor yang Berhubungan dengan Kualitas Hidup Wanita Menopause di Klinik Bank Tabungan Pensiun Nasional (BTPN) Kota Makasssar

Notoatmodjo, S. (2010). Metodologi Penelitian Kesehatan. Jakarta: Rineka Cipta.

Prihatnanto, F. (2013). Hubungan Antara Tingkat Depresi Dengan Kualitas Hidup Lanjut Usia Di Desa Gedongan Kabupaten Sukoharjo Surakarta: Universitas Muhammadiyah Surakarta.

Rapley. (2003). Quality of life Research: acritical Introduction. London: Sage Publications.

Saputra, M. (2011). Depresi pada Wanita Menopause dan Hubungannya dengan Kualitas Hidup.

Smart, A. (2014). Bahagia di Usia Menopause. Yogyakarta: A Plus Books.

WHO. (2012). Depression, a global public health concern. WHO Department of Mental Health and Substance Abuse, 1-8. https://doi.org/10.1007/978-3-64211688-9_20

World Health Organization. (2014). World Health statistics 2014. World Health Organization. https://doi.org/978 9241564588 
Mahakam Midwifery Journal, Vol 2, No. 4, November 2018 : 266-276 